\title{
3, 3'-Diindolylmethane Exhibits Antileukemic Activity In Vitro and In Vivo through a Akt-Dependent Process
}

\author{
Ning Gao ${ }^{1,2 *}$, Senping Cheng ${ }^{2}$, Amit Budhraja ${ }^{2}$, E-Hu Liu' ${ }^{1}$, Jieping Chen ${ }^{3}$, Deying Chen ${ }^{1}$, Zailin Yang ${ }^{3}$, Jia \\ Luo $^{4}$, Xianglin $\mathrm{Shi}^{2}$, Zhuo Zhang ${ }^{2 *}$
}

1 Department of Pharmacognosy, College of Pharmacy, 3rd Military Medical University, Chongqing, China, 2 Graduate Center for Toxicology, College of Medicine, University of Kentucky, Lexington, Kentucky, United States of America, 3 Department of Hematology, Southwest Hospital, 3rd Military Medical University, Chongqing, China, 4 Department of Internal Medicine, University of Kentucky, Lexington, Kentucky, United States of America

\begin{abstract}
3,3'-diindolylmethane (DIM), one of the active products derived from Brassica plants, is a promising antitumor agent. The present study indicated that DIM significantly induced apoptosis in U937 human leukemia cells in dose- and timedependent manners. These events were also noted in other human leukemia cells (Jurkat and HL-60) and primary human leukemia cells (AML) but not in normal bone marrow mononuclear cells. We also found that DIM-induced lethality is associated with caspases activation, myeloid cell leukemia-1 $(\mathrm{Mcl}-1)$ down-regulation, p21 ${ }^{\text {cip } 1 / \text { waf1 }}$ up-regulation, and Akt inactivation accompanied by c-jun NH2-terminal kinase (JNK) activation. Enforced activation of Akt by a constitutively active Akt construct prevented DIM-mediated caspase activation, Mcl-1 down-regulation, JNK activation, and apoptosis. Conversely, DIM lethality was potentiated by the PI3K inhibitor LY294002. Interruption of the JNK pathway by pharmacologic or genetic approaches attenuated DIM-induced caspases activation, Mcl-1 down-regulation, and apoptosis. Lastly, DIM inhibits tumor growth of mouse U937 xenograft, which was related to induction of apoptosis and inactivation of Akt, as well as activation of JNK. Collectively, these findings suggest that DIM induces apoptosis in human leukemia cell lines and primary human leukemia cells, and exhibits antileukemic activity in vivo through Akt inactivation and JNK activation.
\end{abstract}

Citation: Gao N, Cheng S, Budhraja A, Liu E-H, Chen J, et al. (2012) 3, 3'-Diindolylmethane Exhibits Antileukemic Activity In Vitro and In Vivo through a AktDependent Process. PLoS ONE 7(2): e31783. doi:10.1371/journal.pone.0031783

Editor: Kevin D. Bunting, Emory University, United States of America

Received November 2, 2011; Accepted January 16, 2012; Published February 21, 2012

Copyright: (c) 2012 Gao et al. This is an open-access article distributed under the terms of the Creative Commons Attribution License, which permits unrestricted use, distribution, and reproduction in any medium, provided the original author and source are credited.

Funding: The study was supported by NIH Grants RO1 ES015375 (X.Shi), 1R21ES019249 (Zhuo Zhang) and National Natural Science Foundation of China (No. 30971288). The funders had no role in study design, data collection, and analysis, decision to publish, or preparation of the manuscript.

Competing Interests: The authors have declared that no competing interests exist.

*E-mail: zhuo.zhang@uky.edu (ZZ); gaoning59@yahoo.com.cn (NG)

\section{Introduction}

Epidemiological studies have revealed an association between high dietary intake of cruciferous vegetables and decreased cancer risk [1]. The dietary indoles have been shown to be protective against several types of cancers [2]. Indole-3-carbinol (I3C) and 3,3'-diindolylmethane (DIM) are naturally occurring plant alkaloids formed by the hydrolysis of indole glucosinolate (glucobrassicin) and are found in abundance in cruciferous vegetables such as broccoli and Brussels sprouts [3]. I3C is chemically unstable in an acidic environment and is rapidly converted to a variety of condensation products in the stomach. Among those products, DIM is a major one that is readily detectable in the liver and feces of rodents fed with I3C [4]. The parent $\mathrm{I} 3 \mathrm{C}$ could not be detected in tissues of $\mathrm{I} 3 \mathrm{C}$-treated rodents, whereas DIM is acid stable and detectable in biological tissues suggesting that DIM may mediate the physiologic effects of dietary I3C [5], [6]. It has been shown that I3C and DIM exert anticarcinogenic effects in experimental animals and humans [7], [8]. Several studies have also shown that DIM is a potent inhibitor of cell growth and inducer of apoptotic cell death in breast cancer cells [9], [10]. Since DIM is relatively nontoxic to normal tissues of animals and humans [11], it might play an important role in the chemoprevention and chemotherapy of cancers. It has been reported that consumption of cruciferous vegetables appeared to be associated with a decreased risk of leukemia especially AML [12]. Because DIM is a major component of cruciferous vegetables, DIM would be a particularly effective agent for leukemia.

The PI3K/Akt signaling pathway plays an important role in cell survival and anti-apoptotic decisions [13]. A major activator of Akt is phosphatidylinositol-3, 4, 5-triphosphate (PIP3) which is generated by phosphatidylinositol-3- kinase (PI3K) [14]. Akt is activated by phosphorylation at Thr308 by PDK1 or at Ser473 by mTORC2 [15]. Activated Akt functions to promote cell survival by inhibiting apoptosis through inactivation of several proapoptotic factors including Bad, Forkhead transcription factors, and caspase-9 [16], [17], [18]. Akt has been believed to be an attractive target for cancer prevention or treatment.

c-Jun N-terminal kinase (JNK) belongs to the super family of MAP kinases, which can promote apoptosis by different mechanisms [19]. Activation of JNK may result in phosphorylation of c-Jun and activator protein-1 (AP-1) activity, which could drive cells to apoptosis [20]. Previous studies on the role of cell signaling cascades in DIM-mediated lethality have primarily focused on those related to oxidative stress and cell signaling pathways. For example, in MCF-7 human breast cancer cells, DIM induced G1 cell cycle arrest through up-regulation of p21, 
and the oxidative stress and stress-activated signaling cascades including p38 MAPK and JNK play the key roles in these events [21]. It has also been shown that DIM induced apoptosis through inactivation of $\mathrm{NF}-\kappa \mathrm{B}$ in human breast cancer cells [22]. In cholangiocarcinoma cells, Fas mediated apoptosis was enhanced by DIM through inhibition of Akt and FLIP [23]. Furthermore, in human prostate cancer cells, DIM inhibited cell proliferation and induced apoptosis through down-regulation of AR, Akt, and NF$\kappa \mathrm{B}$ signaling [24]. However, neither the effects of DIM on apoptosis induction nor the relationships between DIM lethality and cell signaling cascades been examined in depth in human leukemia. Here, for the first time we reported that DIM significantly induced apoptosis in human leukemia cells. Our results indicate that inactivation of Akt and activation of JNK play important roles in DIM-mediated apoptosis in these cells. Our results also indicate that DIM inhibits growth of mouse U937 xenograft tumors, and the interruptions of the Akt and JNK pathways are involved in DIM-mediated antileukemic activity in vivo.

\section{Results}

DIM induces apoptosis in U937 human leukemia cells in dose- and time-dependent manners

Dose-dependent study revealed a moderate increase in apoptosis $12 \mathrm{~h}$ and $24 \mathrm{~h}$ after exposure to DIM at concentration of $60 \mu \mathrm{M}$ and very extensive apoptosis at concentration of $80 \mu \mathrm{M}$ (Fig. la). Time-course study of cells exposed to $80 \mu \mathrm{M}$ DIM demonstrated a significant increase in apoptosis at $9 \mathrm{~h}$ after drug exposure. These events became apparent after $12 \mathrm{~h}$ of drug exposure, and reached near-maximal levels after $24 \mathrm{~h}$ (Fig. 1a). Consistent with these findings, the same DIM concentrations and exposure intervals resulted in cleavage/activation of caspase-3, -7, -8 and -9 , as well as PARP degradation (Fig. 1b). a

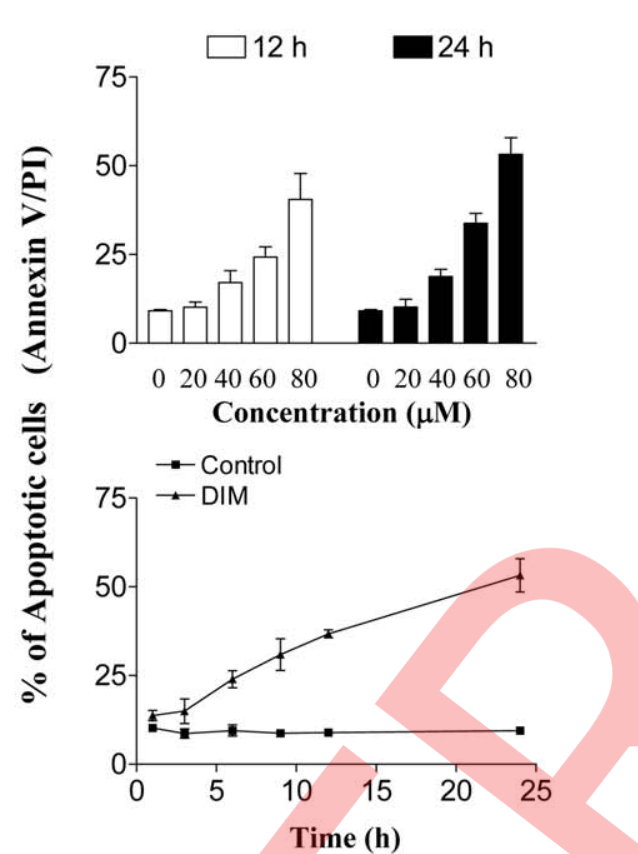

d

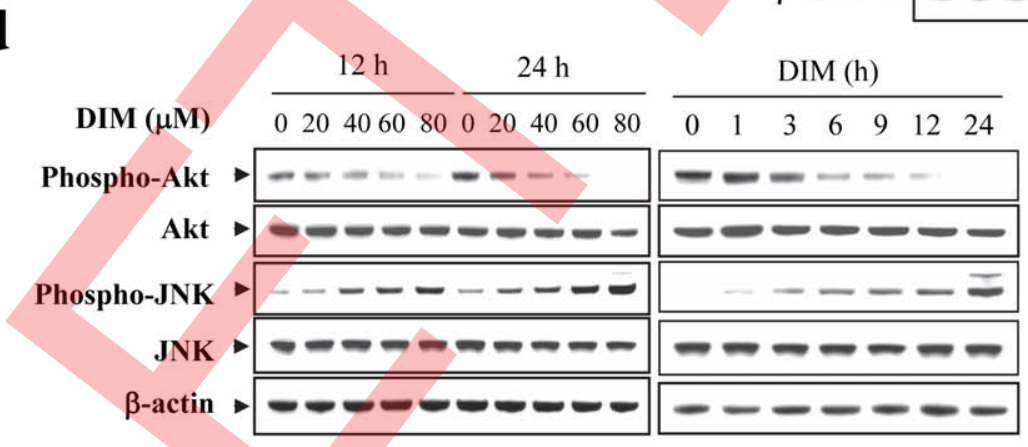

b

$12 \mathrm{~h}$ $24 \mathrm{~h}$ $\operatorname{DIM}(\mathrm{h})$ DIM ( $\mu$ M) $\quad \begin{array}{llllllllllllll}0204060 & 0 & 0 & 20 & 40 & 60 & 80 & 0 & 1 & 3 & 6 & 9 & 12 & 24\end{array}$

c

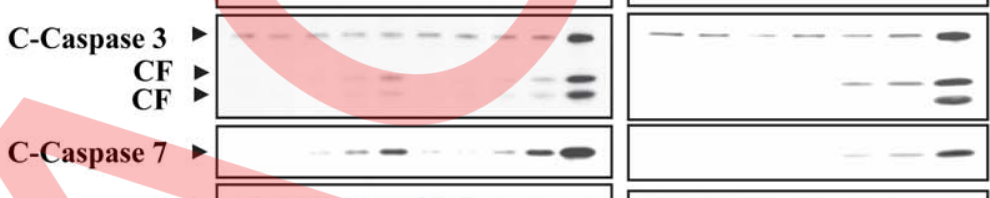

Caspase $8 \triangleright$ -

CF

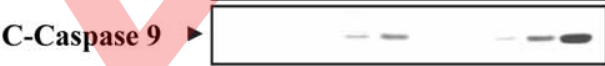

$\beta$-actin $\square-\infty-ー-\infty-0$

$12 \mathrm{~h}$

$24 \mathrm{~h}$
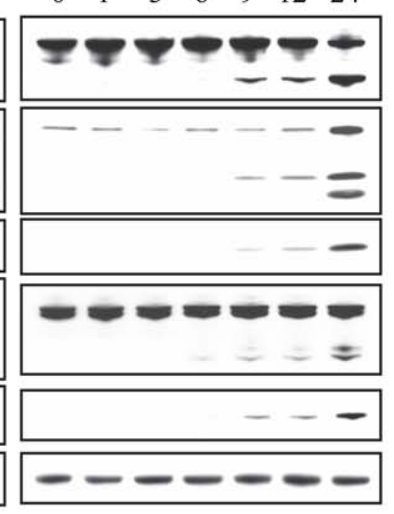

$\operatorname{DIM}(\mathrm{h})$

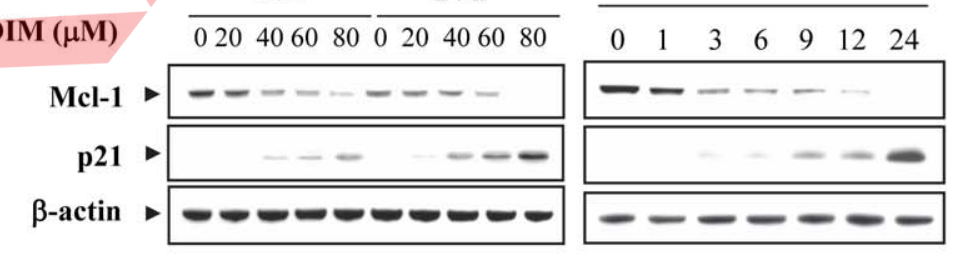

Figure 1. DIM induces apoptosis, caspase activation, downregulation of Mcl-1, upregulation of p21, inactivation of Akt, and activation of JNK in U937 human leukemia cells in dose- and time-dependent manners. U937 cells were treated with various concentrations of DIM as indicated for $12 \mathrm{~h}$ and $24 \mathrm{~h}$ or treated with $80 \mu \mathrm{M}$ DIM for 1, 3, 6, 9, 12, and $24 \mathrm{~h}$. (a) Cells were washed twice with PBS and stained with Annexin V/propidium iodide (PI), and apoptosis was determined using flow cytometry. Both early apoptotic (Annexin V-positive, PInegative) and late apoptotic (Annexin V-positive and PI-positive) cells were included in cell death determinations. The values obtained from annexin $\mathrm{V} / \mathrm{PI}$ assays represent the mean \pm SD for three separate experiments. (b-d) Total cellular extracts were prepared and subjected to Western blot assay using antibodies as indicated.

doi:10.1371/journal.pone.0031783.g001 
Exposure of U937 cells to DIM results in down-regulation of Mcl-1 and up-regulation of p21

The effects of DIM were then examined in relation to expression of various Bcl-2 family members and cell cycle regulatory protein. A dose-dependent study revealed that exposure of U937 cells to DIM at concentration of $40 \mu \mathrm{M}$ resulted in decrease in expression of Mcl-1 and increase in expression of p21. These events became very extensive at concentrations $\geq 60 \mu \mathrm{M}$ (Fig. 1c). Time-course study demonstrated that exposure of U937 cells to $80 \mu \mathrm{M}$ DIM resulted in slight decrease in expression of Mcl-1 as early as $1 \mathrm{~h}$ after drug exposure. This event became apparent after $3 \mathrm{~h}$ of drug exposure, and the expression of Mcl-1 was complete blocked after $12 \mathrm{~h}$ (Fig. 1c). On the other hand, exposure of cells to $80 \mu \mathrm{M}$ DIM resulted in increase in expression of p2 1 at $9 \mathrm{~h}$ after drug exposure, and this event became extensive after $24 \mathrm{~h}$ of drug exposure (Fig. 1c). In contrast, exposure of cells to DIM resulted in little or no change in expression of Bcl-2, Bcl$\mathrm{xL}, \mathrm{Bax}, \mathrm{Bad}$, and Bim (data not shown).

DIM induces inactivation of Akt and activation of JNK in U937 cells

Effects of DIM in U937 cells were also examined in relation to various signaling pathways implicated in apoptosis regulation. Exposure of cells to DIM for $12 \mathrm{~h}$ and $24 \mathrm{~h}$ resulted in diminished phosphorylation of Akt in a dose-dependent manner. This event was accompanied by a pronounced increase in phosphorylation of JNK (Fig. 1d). Time-course study demonstrated that exposure of cells to DIM $(80 \mu \mathrm{M})$ resulted in inhibition of phosphorylation of Akt and activation of JNK as early as $3 \mathrm{~h}$ after drug exposure. These events became apparent at $6 \mathrm{~h}$ and very extensive at $12 \mathrm{~h}$ and $24 \mathrm{~h}$ after drug exposure (Fig. 1d). In contrast, DIM had little or no effect on expression of total or phospho-mTOR, ERK, or p38 MAPK (data not shown). These results suggest that inactivation of Akt and activation of JNK may play important roles in DIM-induced apoptosis.

DIM has similar effects on apoptosis in Jurkat and HL-60 cells, and AML primary leukemia cells

To determine whether these events were restricted to myeloid leukemia cells, parallel studies were performed in Jurkat and HL60 leukemia cells. These cells exhibited apoptotic effects upon DIM exposure similar to those observed in U937 cells although Jurkat and HL-60 cells are less sensitive than U937 cells in DIMinduced apoptosis $(p<0.01$ versus control), PARP degradation, caspases activation (Fig. 2a and $2 \mathrm{~b}$ ).

The effects of DIM on apoptosis in primary leukemia cells from 15 AML patients (four of those patients are M2, five are M4, and six are M5 according to FAB classification system) were

$\mathbf{a}$

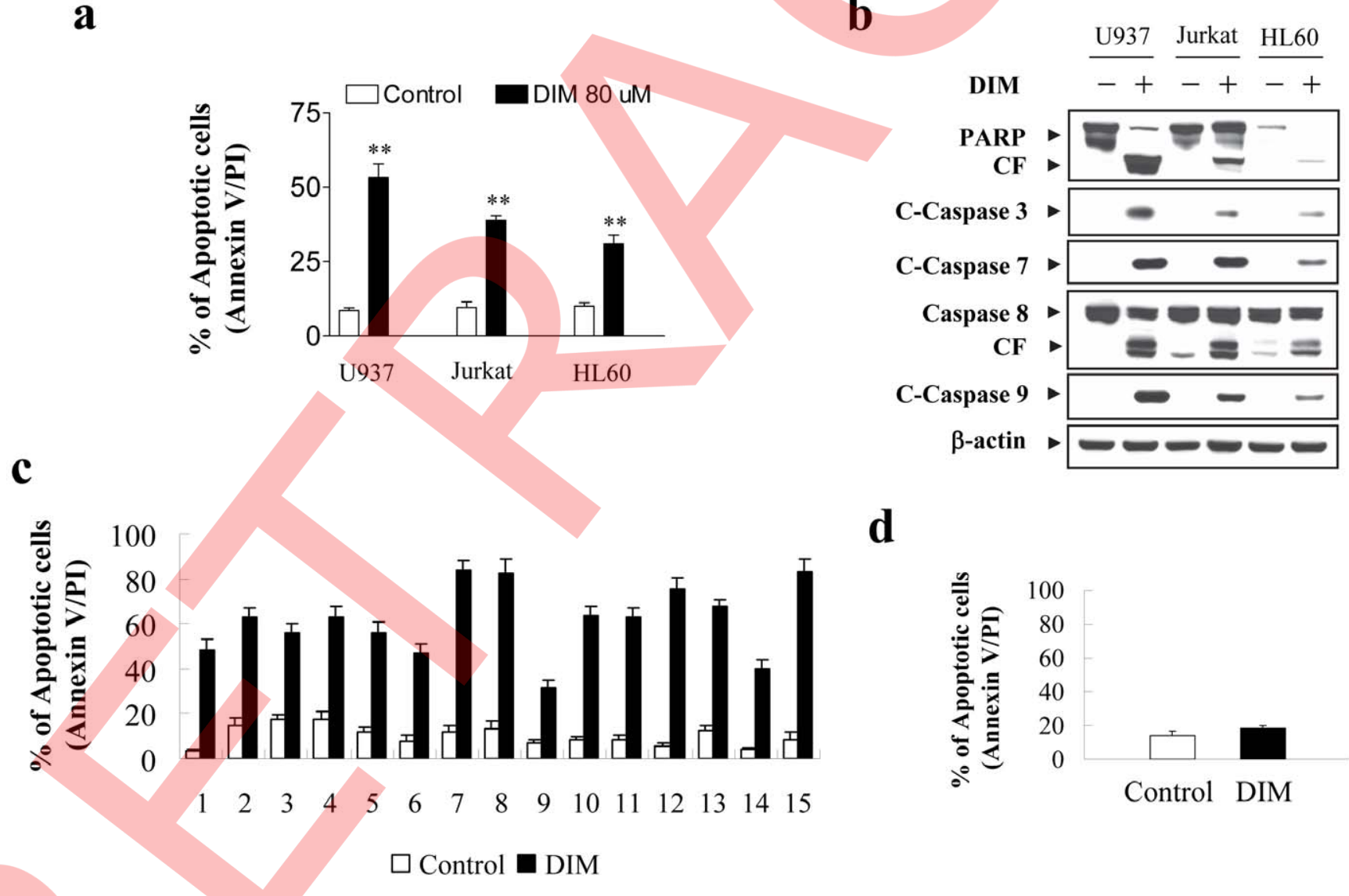

Figure 2. DIM induces apoptosis in U937, Jurkat, and HL-60 cells, and in AML blast samples, but not in normal bone marrow mononuclear cells. (a) U937, Jurkat, and HL-60 cells were treated with $80 \mu \mathrm{M}$ DIM for $24 \mathrm{~h}$, after which apoptosis was determined by annexin V/PI staining and flow cytometry. ${ }^{* *}$ Values for cells treated with DIM were significantly increased compared to values in control cells by Student's t-test, $p<0.01$. (b) Total cellular extracts were prepared and subjected to Western blot analysis using antibodies as indicated. (c-d) Blasts from 15 patients with $\mathrm{AML}$ and normal bone marrow mononuclear cells were treated with $80 \mu \mathrm{M}$ DIM for 24 hours, apoptosis was determined by annexin V/PI staining and flow cytometry.

doi:10.1371/journal.pone.0031783.g002 
investigated. As shown in Fig. 2c, exposure of AML cells to DIM resulted in pronounced increase in apoptosis. Parallel study was also performed with normal bone marrow mononuclear cells. The DIM regimen induced relatively little apoptosis in normal bone marrow mononuclear cells (Fig. 2d). Together, these findings indicate that DIM selectively kills human leukemia cell lines and primary leukemia cells but not normal hematopoietic cells.

DIM-induced apoptosis is associated with the caspaseindependent inactivation of Akt and activation of JNK

To determine whether any of these perturbations mediated by DIM were secondary to caspase-mediated processes, U937 cells were treated with $80 \mu \mathrm{M}$ DIM in the presence of the broadspectrum caspase inhibitor Z-VAD-FMK at $20 \mu \mathrm{M}$. Addition of Z-VAD-FMK, which abrogated DIM-induced apoptosis, PARP degradation, and caspases activation (Fig. 3a and 3b), failed to protect cells from DIM-mediated down-regulation of Mcl-1 and up-regulation of p21 (Fig. 3c). Similarly, Z-VAD-FMK did not attenuate DIM-mediated Akt inactivation and JNK activation (Fig. 3d). Together, these findings suggest that DIM-mediated Akt inactivation, JNK activation, Mcl-1 down-regulation, and p21 up-regulation do not simply reflect activation of the caspase cascade.
Akt inactivation plays an important functional role in DIM-mediated apoptosis

To understand the functional role of Akt inactivation in DIMinduced apoptosis, U937 cells were pretreated with PI3K inhibitor LY294002 for $1 \mathrm{~h}$, followed by treatment with DIM for $24 \mathrm{~h}$, and apoptosis was monitored. As shown in Fig. 4a, co-administration of a nontoxic concentration of LY294002 (i.e. $20 \mu \mathrm{M}$ ) with a modestly toxic concentration of DIM $(40 \mu \mathrm{M}, \sim 25 \%$ apoptosis at $24 \mathrm{~h}$ ) resulted a pronounced increase in apoptosis ( $\sim 60 \%$ at $24 \mathrm{~h})$. Western blot analysis demonstrated that co-administration of DIM and LY294002 resulted in pronounced increase in caspases activation and PARP degradation (Fig. 4b). Combined treatment with DIM and LY294002 also resulted in potentiation of Mcl-1 down-regulation, Akt inactivation and pronounced increase in JNK activation (Fig. 4c). Together, these findings suggest that inactivation of Akt plays a critical role in DIM-induced apoptosis in human leukemia cells.

To further assess the functional significance of Akt inactivation in DIM-mediated lethality, U937 cells ectopically expressing AktCA and Akt-DN were employed. As shown in Fig. 4d, Akt-CA cells were markedly less sensitive to DIM-induced apoptosis than pcDNA3.1 vector control cells $(p<0.01)$. However, DIM-induced apoptosis in Akt-DN cells is similar to that in pcDNA3.1 control

a

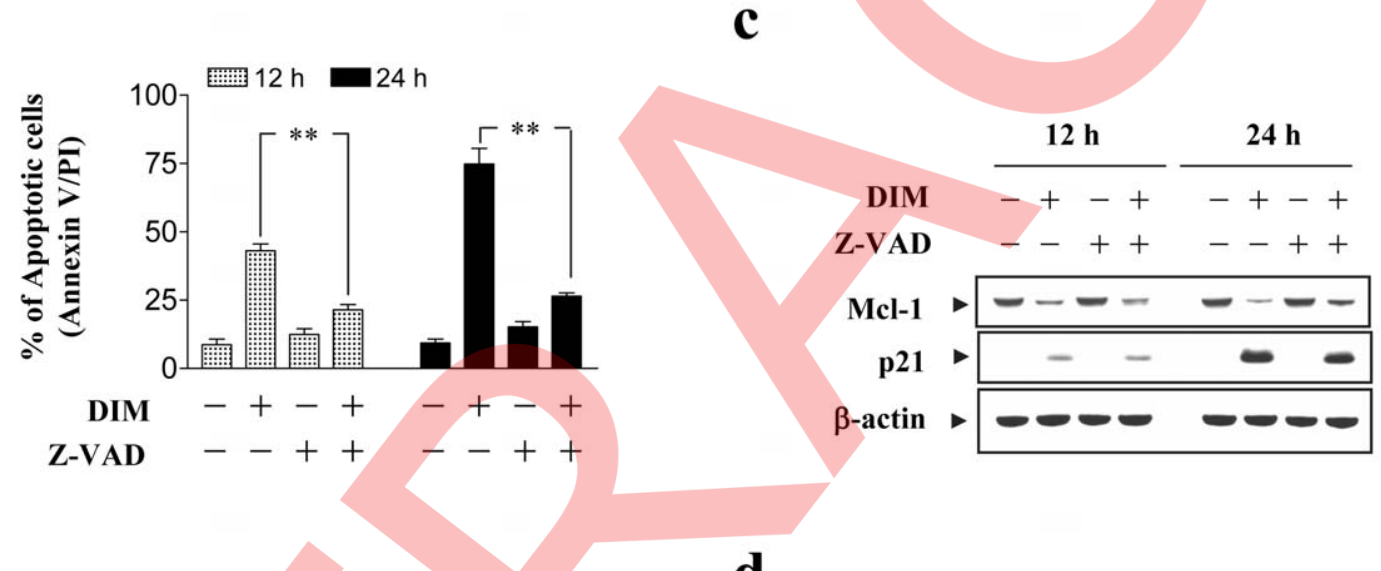

b

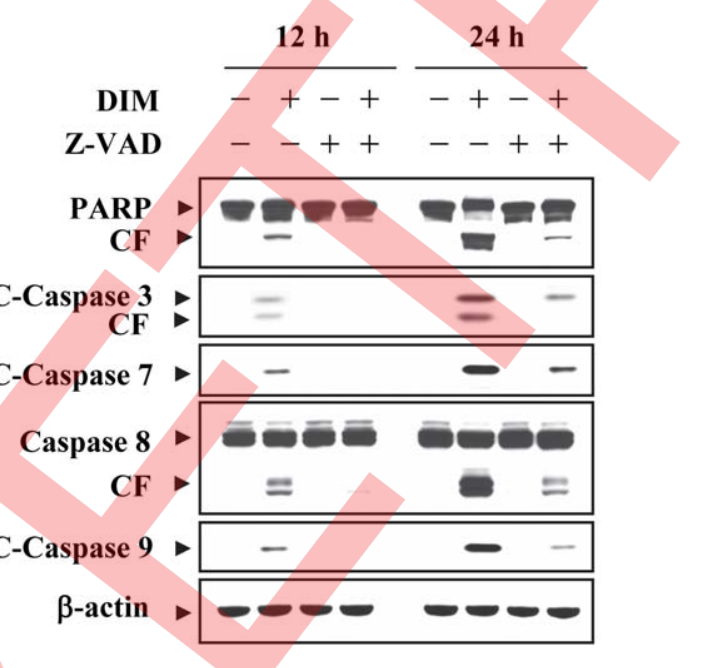

d

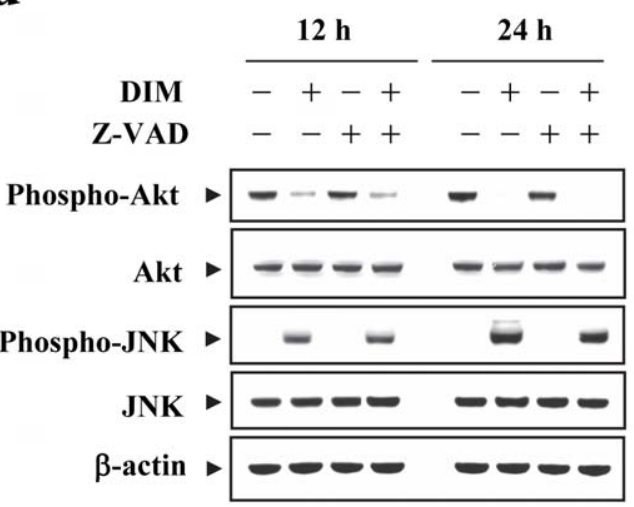

Figure 3. Effects of inhibition of caspases by Z-VAD-FMK on apoptosis, expression of Mcl-1 and p21, and phosphorylation of Akt and JNK. U937 cells were pretreated with the caspase inhibitor Z-VAD-FMK $(20 \mu \mathrm{M})$ for $1 \mathrm{~h}$, followed by treatment with $80 \mu \mathrm{M}$ DIM for $12 \mathrm{~h}$ and $24 \mathrm{~h}$. (a) Cells were stained with Annexin V/PI, and apoptosis was determined using flow cytometry. ${ }^{*}$ Values for cells treated with DIM and Z-VADFMK were significantly reduced compared to values obtained for DIM alone by Student's t-test, $p<0.01$. (b-d) Total protein extracts were prepared and subjected to Western blot assay using antibodies as indicated.

doi:10.1371/journal.pone.0031783.g003 
a

d

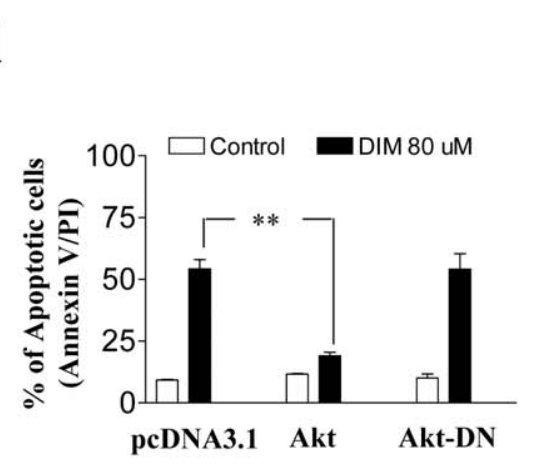

b

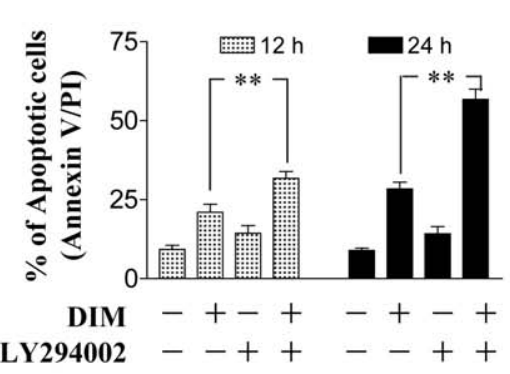

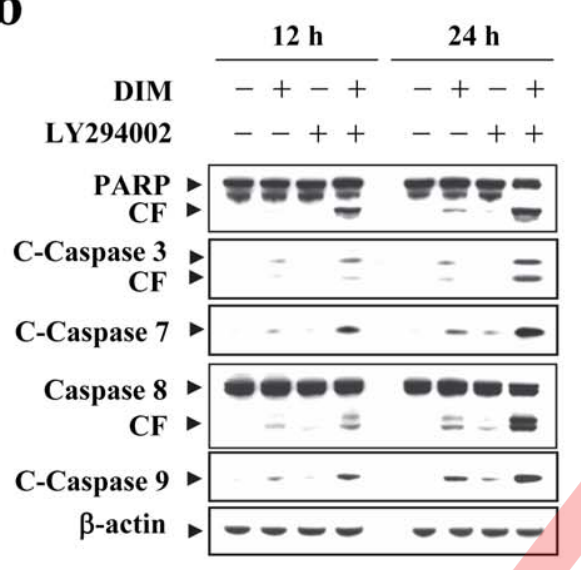

e

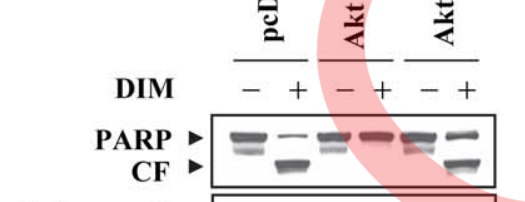

C-Caspase $3 \triangleright--$

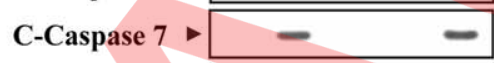

Caspase $8 \rightarrow \square=0$

CF

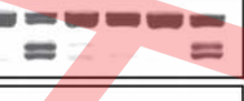

C-Caspase 9

$\beta$-actin

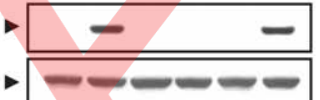

c

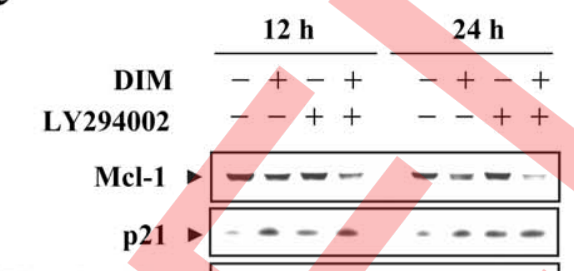

Phospho-Akt $\rightarrow-\infty-\cdots$
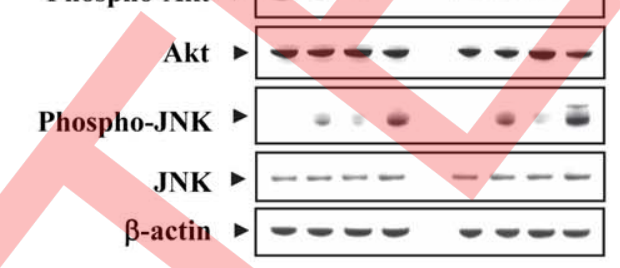

f
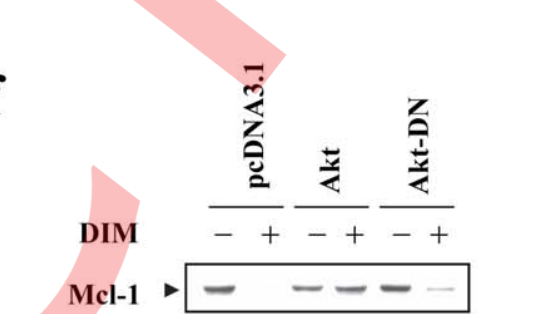

Phospho-Akt

Phospho-JNK $\square=$

JNK $\triangleright------$

$\beta$-actin $-\infty-\infty$

Figure 4. Effects of PI3K inhibitor, LY294002 (LY) and genetic activation of Akt on apoptosis induced by DIM. U937 cells were pretreated with $20 \mu \mathrm{M}$ of LY for $1 \mathrm{~h}$, followed by the addition of $40 \mu \mathrm{M}$ of DIM for $24 \mathrm{~h}$. (a) Cells were stained with Annexin V/PI, and apoptosis was determined using flow cytometry. ${ }^{*}$ Values for cells treated with DIM and LY were significantly greater than those for cells treated with DIM alone by Student's $t$-test; $p<0.01$. (b-c) Total cellular extracts were prepared and subjected to Western blot analysis using antibodies as indicated. (d) U937 cells were stably transfected with an empty vector (pcDNA3.1), Akt-CA, and Akt-DN. Cells were treated with $80 \mu \mathrm{M}$ of DIM for $24 \mathrm{~h}$, after which apoptosis was analysed using Annexin V/PI assay. ${ }^{* *}$ Values for Akt-CA cells treated with DIM were significantly decreased compared to those for pCDNA3.1 cells by Student's $t$-test, $p<0.01$. (e-f) Total cellular extracts were prepared and subjected to Western blot analysis using antibodies as indicated.

doi:10.1371/journal.pone.0031783.g004

cells. Consistent with these findings, DIM was considerably less effective in triggering caspases activation and PARP degradation in Akt-CA cells compared to pcDNA3.1 vector control cells and Akt-DN cells (Fig. 4e). In addition, enforced activation of Akt effectively blocked DIM-mediated Mcl-1 down-regulation (Fig. 4f). Western blot analysis displayed marked increase in levels of total and phospho-Akt in Akt-CA cells. DIM failed to induce inactivation of Akt in these Akt-CA cells (Fig. 4f). Interestingly, the ability of DIM to induce JNK activation was essentially abrogated in Akt-CA cells (Fig. 4f), indicating that activation of JNK mediated by DIM depends upon inactivation of Akt.

JNK activation plays an important functional role in DIMmediated apoptosis

To understand the functional significance of JNK activation in DIM-induced apoptosis, both pharmacologic and genetic approaches were employed. Pretreatment with JNK inhibitor SP600125 (i.e. $10 \mu \mathrm{M}$ ) essentially abrogated DIM-induced apoptosis (Fig. 5a), caspases activation, and PARP degradation
(Fig. 5b). Co-administration of SP600125 also blocked Mcl-1 down-regulation and effectively diminished phosphorylation of JNK mediated by DIM (Fig. 5c). To further confirm the functional role of JNK in DIM-induced apoptosis, a genetic approach utilizing JNK1 siRNA was employed. As shown in Fig. 5d, transient transfection of U937 cells with JNK1 siRNA reduced expression of $\mathrm{JNK} 1$, and resulted in a significant reduction in DIM-mediated apoptosis. Collectively, these findings indicate that DIM-induced JNK activation plays an important functional role in DIM-related lethality.

\section{DIM inhibits growth of a U937 tumor xenograft in} immunodeficient Mice

Finally, we evaluated whether our in vitro observations could be translated into an animal model system in vivo. To address this issue, NOD/SCID mice were inoculated in the flank with U937 human leukemia cells, after which mice were treated daily intraperitoneally with either vehicle or DIM $(50 \mathrm{mg} / \mathrm{kg}$ ) for 20 days and tumors were measured. As shown in Fig. 6a, treatment 


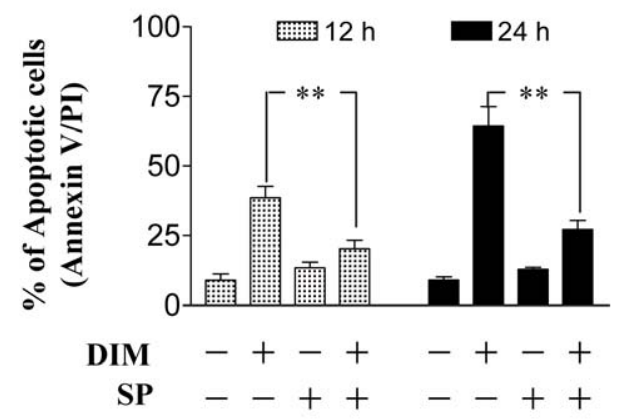

C

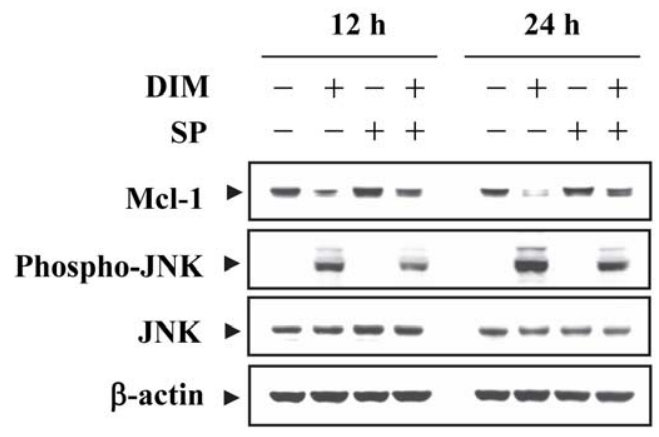

b
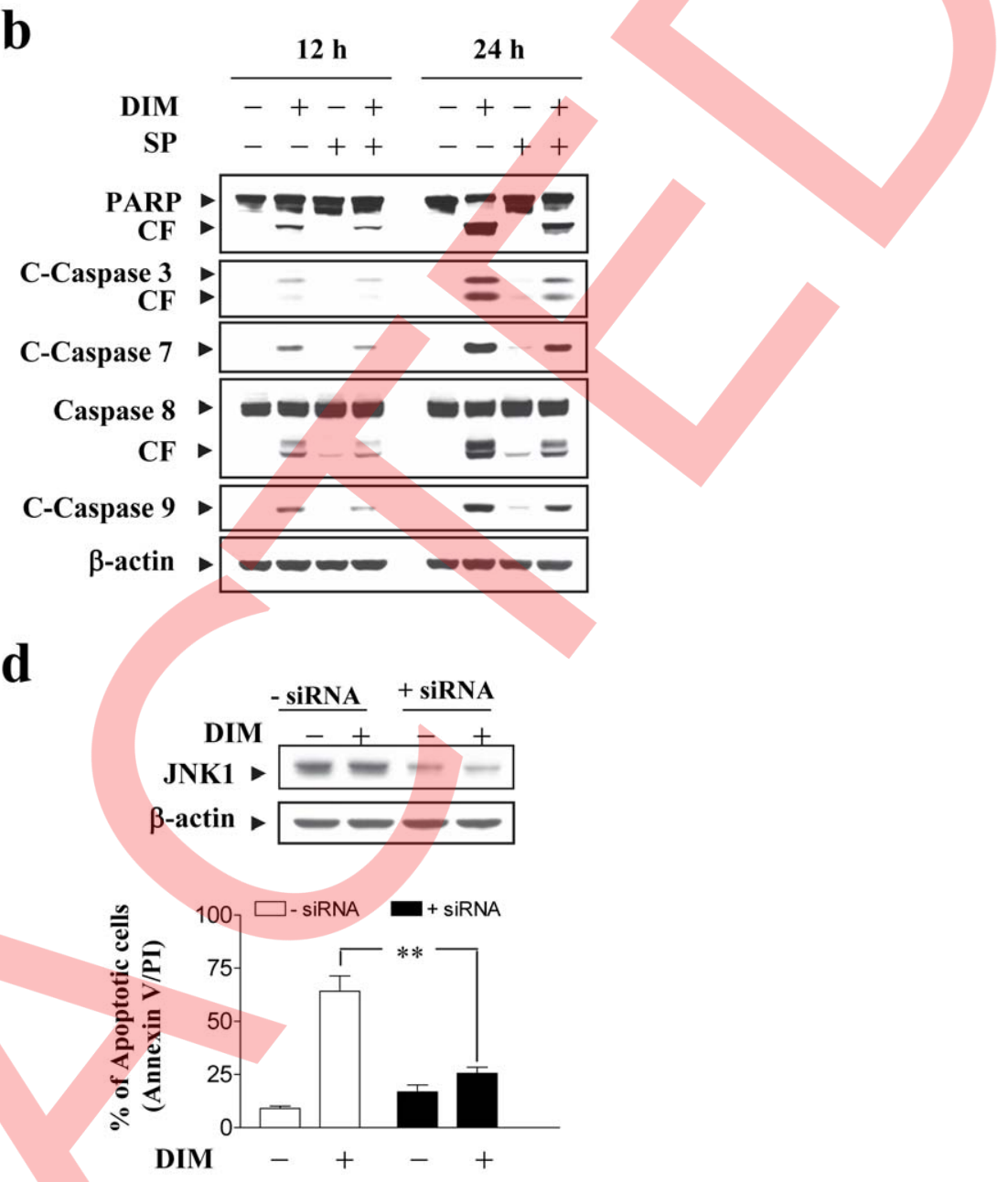

Figure 5. Inhibition of JNK significantly protect cells from DIM-induced apoptosis. U937 cells were pretreated with $10 \mu \mathrm{M}$ of JNK inhibitor, SP600125 (SP), for $1 \mathrm{~h}$, followed by the addition of $80 \mu \mathrm{M}$ of DIM for $24 \mathrm{~h}$. (a) Cells were stained with Annexin V/PI, and apoptosis was determined using flow cytometry. **Values for cells treated with DIM and SP were significantly less than those obtained for cells treated with DIM alone by Student's t-test, $p<0.01$. (b-c) Total cellular extracts were prepared and subjected to Western blot assay using antibodies as indicated. (d) U937 cells were transfected with JNK1 siRNA oligonucleotides or controls and incubated for $24 \mathrm{~h}$ at $37^{\circ} \mathrm{C}$, after which cells were treated with $80 \mu \mathrm{M}$ of DIM for $24 \mathrm{~h}$. Apoptosis was determined using the Annexin V/PI assay. ${ }^{*}$ Values for cells treated with DIM after transfection with JNK1 siRNA were significantly decreased compared to those for control cells treated with DIM by Student's t-test; $p<0.01$. Total cellular extracts were prepared and subjected to Western blot analysis using antibodies against JNK1.

doi:10.1371/journal.pone.0031783.g005

with DIM resulted in a dramatic suppression of tumor growth of U937 xenograft ( $p<0.01$ compared with vehicle control), whereas 20 days following drug exposure no statistically significant change in body weight was noted comparing vehicle control (Fig. 6b), suggesting that no severe toxicity was observed. Tumors exposed to DIM compared with vehicle control exhibited a reduced number of cells per field under $\mathrm{H} \& \mathrm{E}$ staining, with signs of necrosis with infiltration of inflammatory cells (i.e. phagocytic cells), fibrosis, as well as apoptotic regions (Fig. 6c top panels). Moreover, treatment with DIM resulted in a striking induction of apoptosis in tumor cells determined by TUNEL analysis (Fig. 6c middle panels). Exposure to DIM also caused marked increase in immunoreactivity for the cleaved caspase-3 (Fig. 6c bottom panels).

Lastly, we performed the immunohistochemistry analysis to evaluate the expression of Mcl-1, phospho-Akt, and phospho-JNK in tissue sections of U937 xenografts. As expected, tumors from vehicle-treated control mice stained strongly for Mcl-1 and phospho-Akt, which were immunolocalized to the cytoplasm of cancer cells. Treatment with DIM resulted in markedly decrease in expression of Mcl-1 (Fig. 6d top panels) and phospho-Akt in tissue sections of tumors (Fig. 6d middle panels). Furthermore, immunostaining of tumors from mice treated with DIM showed marked increase in phospho-JNK (Fig. 6d bottom panels). Collectively, these findings demonstrated that DIM administration significantly inhibited U937 xenograft growth without causing any side effects to the mice. DIM-mediated antileukemic activity in vivo is associated with inactivation of Akt and activation of JNK.

\section{Discussion}

The present study shows that exposure of U937 human leukemia cells resulted in increase in apoptosis in dose- and time-dependent manners. In addition, our results provide mechanistic information, for the first time, how DIM exerts its proapoptotic effects on human leukemia cells (i.e. by inhibiting phosphorylation of Akt and expression of Mcl-1, and by inducing phosphorylation of JNK and the expression of p21). Experimental 
a

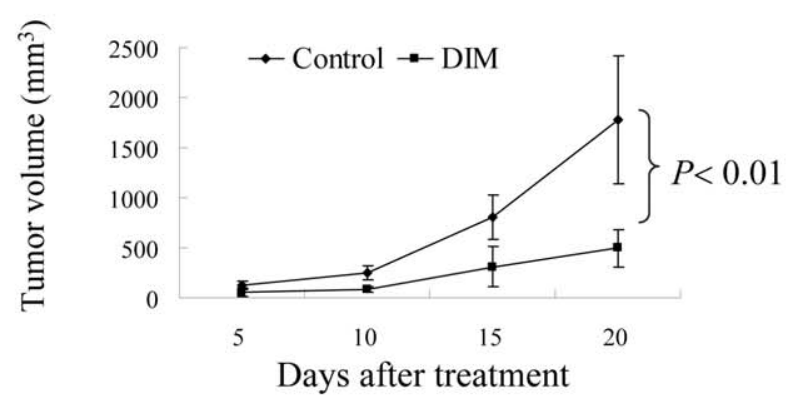

b

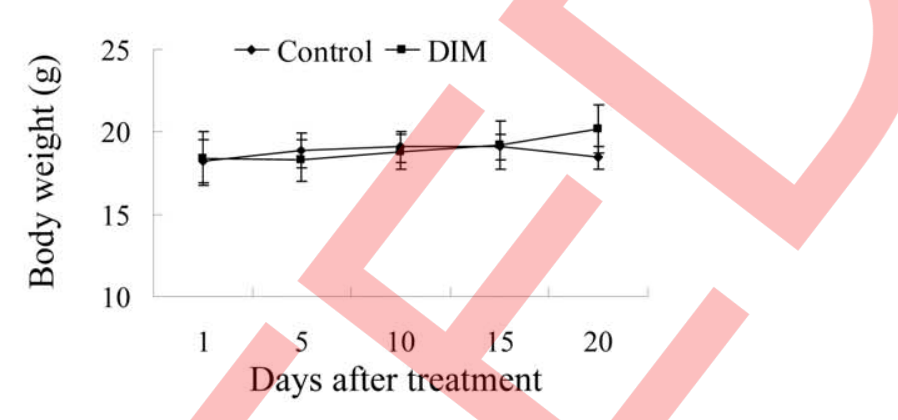

c

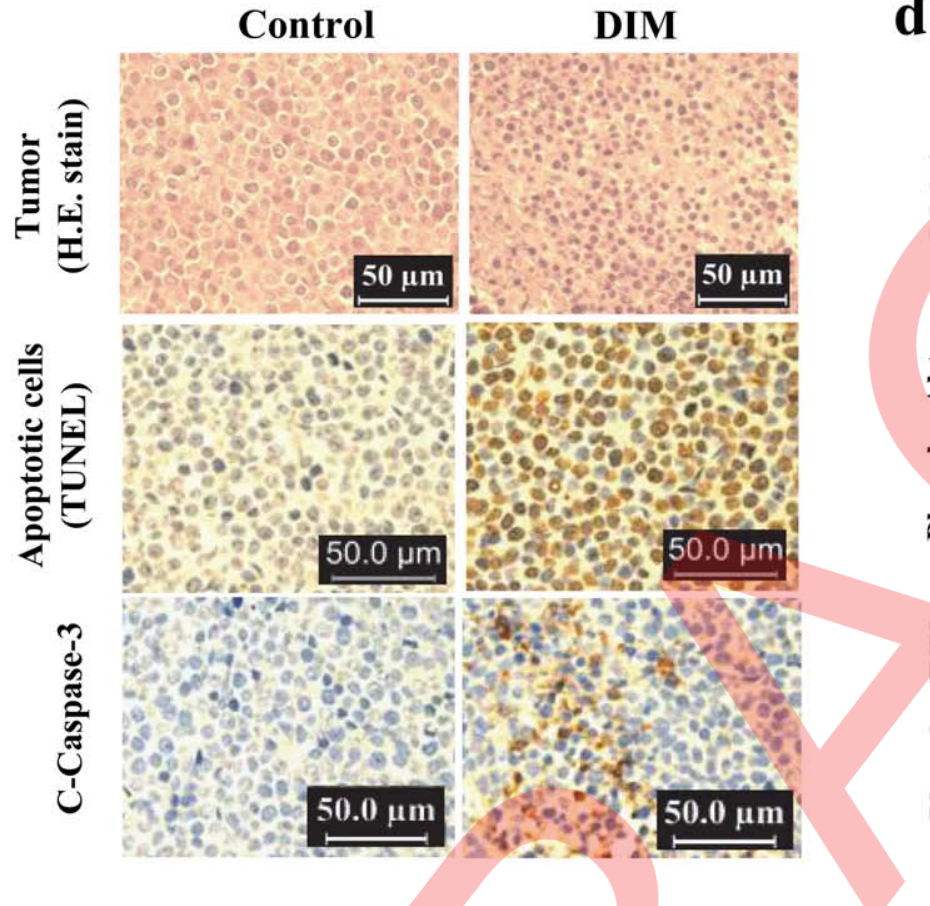

d

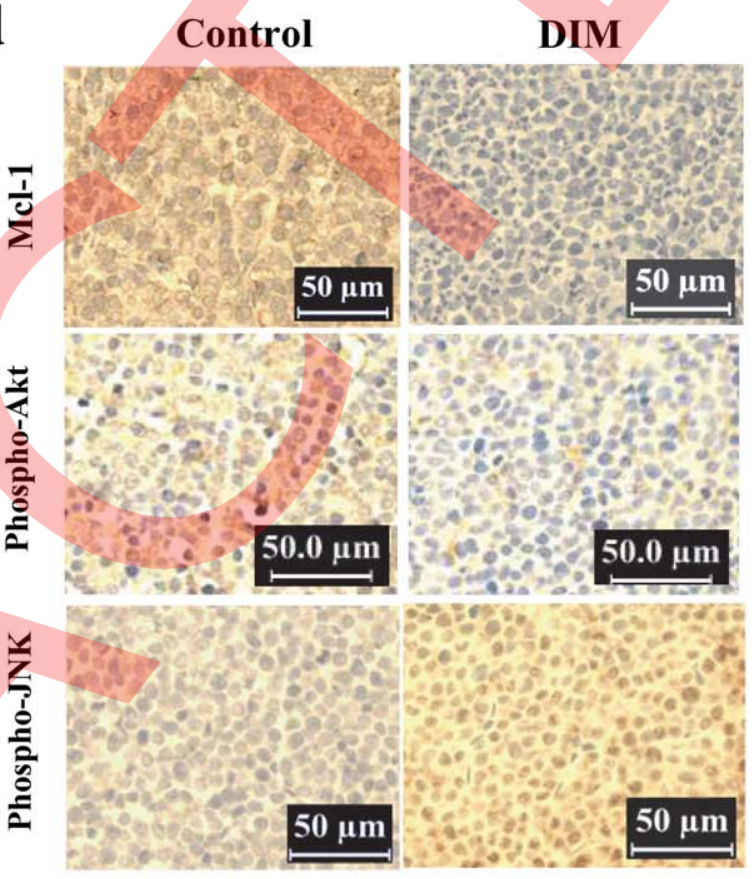

Figure 6. In vivo antileukemic activity of DIM in U937 xenografts. 20 NOD/SCID mice were inoculated with U937 cells $\left(2 \times 10^{6}\right.$ cells/mouse, i.p.) and randomly divided into two groups (10/group) for treatment with DIM (50 mg/kg, i.p., daily, five times per week) or with vehicle control solvent. (a) Average tumor volume in vehicle control mice and mice treated with $50 \mathrm{mg} / \mathrm{kg}$ DIM. $P<0.01$, significantly different compared with vehicle control by Student's $t$-test. (b) body weight changes of mice during the 20 days of study. (c) At the 20 days after DIM treatment, the tumors were excised and subjected to H\&E staining for determination of pathological evaluation, TUNEL assay for determination of apoptosis, and immunohistochemical staining to determine Cleavage-caspase- 3 immunoreactivity. Original magnification $\times 400$. (d) After treatment with DIM, tumor tissues were sectioned and subjected to immunohistochemistry using anbibodies as indicated.

doi:10.1371/journal.pone.0031783.g006

studies have revealed that DIM induces apoptosis in a variety of cancer cells including breast and prostate cancer cells through different cell signaling pathways including NF- $\mathrm{B}$, Akt, MAPK, p53, AR, and ER pathways [22], [24], [25]. Presently, no information is available concerning the functional roles of the Akt and JNK pathways in mediating in DIM-induced lethality, particularly in malignant hematopoietic cells. The results of the present study demonstrate that Akt inactivation and JNK activation play key functional contributions in caspase activation and subsequent lethality.

Akt is a serine-threonine kinase, which has been shown to be activated in various cancers [26]. Akt plays a critical role in cell survival through multiple downstream targets [27], [28]. Akt is activated by PI3K, which in turn is regulated by the PTEN phosphatase [29], mutations of which are among the most commonly encountered in human cancers [30]. Akt activation generally involves PTEN inactivation [31], and results in attenuation of lethality [32]. The present findings show that
DIM exposure resulted in diminished Akt phosphorylation. While it would be tempting to attribute this phenomenon to PTEN activation, the fact that U937 cells do not express wild-type PTEN argues against this notion [33]. A more likely possibility is that DIM, through a mechanism not yet elucidated blocks the actions of PI3K. The finding that LY294002, an inhibitor of PI3K, enhanced DIM-mediated inhibition of Akt and lethality is potentially consistent with this hypothesis. It should also be noted that various stimuli induce apoptosis by different mechanisms linked between Akt inactivation and caspase activation. The caspase-dependent down-regulation of Akt is a well-described positive feedback regulation. For example, previous study demonstrated that 4-Hydroxynonenal (HNE)-mediated Akt inactivation was caspase-3-dependent [34]. However, our previous results indicate that inactivation of Akt by 2-methoxyestradiol does not simply represent a secondary, caspase-dependent event [35]. In this study, co-treatment of cells with the caspase inhibitor ZVAD-FMK failed to prevent Akt inactivation. Such findings 
indicate that inactivation of Akt by DIM does not simply represent a secondary caspase- dependent event.

A number of evidence suggests that in human leukemia cells, DIM-induced Akt inactivation plays a critical role in DIMmediated lethality. First, co-administration of LY294002 significantly enhanced DIM-mediated caspases activation and apoptosis. Second, enforced activation of Akt largely reversed the lethal consequences of DIM. Particularly, DIM exposure resulted in down-regulation of Mcl-1, an anti-apoptotic protein that may play an important role in regulating apoptosis in malignant hematopoietic cells [36]. Mcl-1 has a short half-life and is a highly regulated protein, induced by a wide range of survival signals and rapidly down regulated during apoptosis [37]. Although the precise mechanism underlying the Mcl-1 reduction upon DIM treatment remains to be elucidated, interventions disabling Mcl-1 may be an optimal way to kill leukemia cells. It has been reported that the anti-apoptotic gene Mcl-1 is up-regulated by the PI3K/ Akt signaling pathway [38], and down-regulation of Mcl-1 by inhibition of PI3K/Akt pathway is required for cell death [39]. The finding that enforced activation of Akt largely blocked DIMmediated down-regulation of Mcl-1 may significantly contribute to DIM-mediated lethality. However, additional mechanistic studies are required to demonstrate the causative role of Mcl-1 in DIM induced lethality in leukemia.

Induction of apoptosis was also associated with activation of JNK pathway. Engagement of the SEK/JNK pathway has been shown to play a key functional role in the lethal effects of diverse cytotoxic stimuli, including inflammation and oxidative stress [40]. In fact, the net balance between cytoprotective (e.g. ERK) and stress-related (e.g. JNK) signaling may play a critical role in cell survival and death decisions [41]. The finding that pharmacologic and genetic interruption of the JNK pathway attenuated DIMmediated lethality indicates that stress pathway play a critical role in apoptosis induction by this agent. The mechanism by which oxidative stress triggers JNK activation is not known with certainty, but may involve release from GSH-mediated inhibitory effects, or alternatively, perturbations in thioredoxin, leading to activation of ASK-1 (apoptosis signal-regulating kinase-1), of which JNK is a downstream target [42], [43]. Interestingly, ectopic expression of Akt not only blocked DIM-mediated caspases activation and apoptosis but also prevented the striking increase in JNK activation, raising the possibility that one of the mechanisms by which Akt protects cells from DIM lethality is by opposing JNK activation. Evidence that the Akt-mediated inhibition of SEK 1 and/or ASK1 may act as a negative regulation of the JNK pathway through Akt-dependent induction of specific JNKinteracting protein (JIP) provides a possible explanation for this phenomenon [44]. Lastly, the observation that pharmacologic or genetic interruption of the JNK pathway attenuated DIMmediated caspases activation and lethality demonstrates an important functional role for this stress pathway in triggering the cell death program. Such findings are compatible with previous reports suggesting a direct role for JNK activation in promoting cytochrome $c$ release from the mitochondria [45].

Our present study has revealed that DIM causes up-regulation of Cip/p21 expression in human leukemia cells. p21 protein is an inhibitor of cyclin-dependent kinase (CDK) and plays an important role in regulating CDK activity and cell cycle progression in response to a wide variety of stimuli [46]. In addition to normal cell cycle progression, p2 1 has been postulated to participate in growth suppression and apoptosis through a p53dependent or -independent pathway following stress and induction of p21 may cause cell cycle arrest [47], [48]. In a recent study, DIM has been shown to inhibit cell growth and induce G1 phase cell cycle arrest in human breast cancer cells through Cipl/p21 up-regulation [21]. Consistent with this result, DIM-mediated apoptosis in human leukemia cells may be associated with Cip/ p21 up-regulation and cell cycle arrest. Additional mechanistic studies, however, are required in future to elucidate how Cipl/ p21 plays a role in DIM-induced apoptosis in human leukemia cells.

Our study reported that DIM induces apoptosis in diverse human leukemia cell lines (i.e. U937, Jurkat, and HL-60) and primary human AML blast cells, and cell-signaling pathways including Akt inactivation and JNK activation may be involved in these events. However, it is still unclear whether the underlying mechanism of apoptosis in vitro is identical to those in vivo. Our present results showed that treatment with DIM could inhibit tumor growth in U937 tumor xenograft model that could be mechanistically linked with inactivation of Akt and activation of JNK. These results further confirmed that inactivation of Akt and activation of JNK could play an important role in DIM-induced apoptosis in vivo.

In summary, the present study has provided evidence that DIM induces human leukemia cell death with caspases activation and PARP cleavage, and that DIM-induced apoptosis proceeds via inactivation of Akt, activation of $\mathrm{JNK}$, and down-regulation of Mcl-1. The data presented here suggest that Akt and JNK signaling pathways may represent attractive targets for DIMinduced apoptosis in human leukemia cells in vitro and in vivo. The results of the present study could have important implications for the incorporation of agents such as DIM into the chemopreventive or therapeutic intervention against leukemia and possibly other hematologic malignancies.

\section{Materials and Methods}

\section{Chemicals and reagents}

DIM was purchased from Sigma (St Louis, MO). LY294002, SP600125, and Z-VAD-FMK were from EMD Biosciences (La Jolla, CA). Antibodies against Akt, phospho-JNK, JNK, and $\beta$ actin were from Santa Cruz (Santa Cruz, CA). Cleaved-caspase-3, Cleaved-caspase-7, Cleaved-capase-9, and phospho-Akt (Ser473) were from Cell Signaling (Beverly, MA). Mcl-1 and p21 were from PharMingen (San Diego, CA). PARP was from Biomol (Plymouth Meeting, PA). Caspase-8 was from Alexis (Carlsbad, CA).

\section{Cell culture and transfection}

U937, HL-60, and Jurkat cells were provided by American Type Culture Collection (ATCG, Manassas, VA) and maintained in RPMI 1640 medium containing 10\% fetal bovine serum (FBS). The constitutive active form of Akt (Akt-CA) and the dominant negative Akt mutant (Akt-DN) were kindly provided by Dr. Richard Roth (Stanford University, School of Medicine, Stanford, CA), and were subcloned into the pcDNA3.1. U937 cells were stably transfected with Akt-CA and Akt-DN using the Amaxa nucleofector $^{\mathrm{TM}}$ (Koeln, Germany) as recommended by the manufacturer. Stable single cell clones were selected in the presence of $400 \mu \mathrm{g} / \mathrm{ml}$ of geneticin. Thereafter, the expression of Akt from each cell clone was analyzed by Western blot analysis.

Peripheral-blood samples for the in vitro studies were obtained from 15 patients with newly diagnosed or recurrent acute myeloid leukemia (AML) after informed consent. The percentage of AML cells from each patient were greater than 20\%. According to French-American-British (FAB) classification system, 4 patients are M2, 5 patients are M4, and 6 patients are M5. Approval was obtained from the Southwest Hospital (Chongqing, China) institutional review board for these studies. AML blasts were 
isolated by density gradient centrifugation over Histopaque-1077 (Sigma Diagnostics, St Louis, MO) at $400 \mathrm{~g}$ for 30 minutes. Isolated mononuclear cells were washed and assayed for total number and viability using trypan blue exclusion. Cells were suspended at $8 \times 10^{5} / \mathrm{mL}$ for treatment. Fresh normal bone marrow mononuclear cells were purchased from Allcells (Emeryvill, CA). After washing and enumerating, cells were suspended at $8 \times 10^{5} / \mathrm{mL}$ prior to treatment.

\section{RNA interference and transfection}

U937cells $\left(1.5 \times 10^{6}\right)$ were transfected with $1 \mu \mathrm{g}$ JNK1-annealed dsRNAi oligonucleotide 5'-CGUGGGAUUUAUGGUGUGUGTT-3' / 3 '-TTGGACGUAAAUACGAGACAC-5' (Orbigen, San Diego, CA, USA) using the Amaxa nucleofectort (Koeln, Germany) as recommended by the manufacturer. After incubation at $37^{\circ} \mathrm{C}$ for $24 \mathrm{~h}$, transfected cells were treated with DIM, and subjected to determination of apoptosis and JNK1 expression using Annexin V/PI and flow cytometry and Western blot analysis.

\section{Assessment of apoptosis}

The extent of apoptosis in leukemia cells was evaluated by flow cytometric analysis using FITC conjugated Annexin V/propidium iodide (BD PharMingen, San Diego, CA) staining according to the manufacturer's instructions. Both early apoptotic (Annexin Vpositive, PI-negative) and late apoptotic (Annexin V-positive and PI-positive) cells were included in cell death determinations.

\section{Western blot analysis}

The total cellular samples were washed twice with ice-cold PBS and lysed in $1 \times$ NuPAGE LDS sample buffer supplemented with $50 \mathrm{mM}$ dithiothreitol. The protein concentration was determined using Coomassie Protein Assay Reagent (Pierce, Rockford, IL). $30 \mu \mathrm{g}$ of sample proteins were separated by SDS-PAGE and transferred to nitrocellulose membrane. Membranes were blocked with $5 \%$ fat-free dry milk in $1 \times$ Tris-buffered saline (TBS) and incubated with antibodies. Protein bands were detected by incubating with horseradish peroxidase-conjugated antibodies (Kirkegaard and Perry Laboratories, Gaithersburg, MD) and visualized with enhanced chemiluminescence reagent (Perkin Elmer, Boston, MA).

\section{Xenograft assay}

NOD/SCID (severe combined immunedeficient) mice (5 weeks old) were purchased from Vital River Laboratories (VRL, Beijing, China). All animal studies were conducted according to protocols approved by the Institutional Animal Care and Use Committee (IACUC) of Third Military Medical University (Approval ID: 2009020014). U937 cells $\left(2 \times 10^{6} / 0.2 \mathrm{~mL} /\right.$ mouse) were suspended in sterile PBS and injected s.c. into the right flank of the mice. Mice were randomized into two groups (10 mice/group). Three days after tumor inoculation, the treatment group received DIM (50 mg/kg, i.p., five times per week). The control group received an equal volume of solvent control. Tumor size and body weight were measured after treatment at various time intervals through-

\section{References}

1. Seymour JD, Calle EE, Flagg EW, Coates RJ, Ford ES, et al. (2003) Diet quality index as a predictor of short-term mortality in the American Cancer Society Cancer Prevention Study II Nutrition Cohort. Am J Epidemiol 157: 980-988.

2. Steinmetz KA, Potter JD (1991) Vegetables, fruit, and cancer. I. Epidemiology. Cancer Causes Control 2: 325-357.

McDanel R, McLean AE, Hanley AB, Heaney RK, Fenwick GR (1988) Chemical and biological properties of indole glucosinolates (glucobrassicin): A review. Food Chem Toxicol 26: 59-70. out the study. At the termination of the experiment, mice were sacrificed at $24 \mathrm{~h}$ after the last administration. The tumors were excised and weighed. Tumors were collected at selected times and fixed in paraformaldehyde. Paraffin-embedded tissues were sectioned and processed for TUNEL staining and immunohistochemical staining.

\section{TUNEL assay}

The apoptotic cells in tissue samples were detected using an In Situ Cell Death Detection kit (Roche Diagnostics, Mannheim, Germany) according to the manufacturer's manual. After deparaffinization and permeabilization, the tissue sections were incubated in proteinase $\mathrm{K}$ for $15 \mathrm{~min}$ at room temperature. The sections were then incubated with the TUNEL reaction mixture that contains terminal deoxynucleotidyl transferase (TdT) and fluorescein-dUTP at $37^{\circ} \mathrm{C}$ for $1 \mathrm{~h}$. After washing three times with PBS, the sections were incubated with the Converter-POD which contains anti-fluorescein antibody conjugated with horse-radish peroxidase (POD) at room temperature for 30 minutes. After washing three times with PBS, the sections were incubated with $0.05 \%$ 3-3'-diaminobenzidine tetrahydrochloride (DAB) and analyzed under light microscope.

\section{Histological and immunohistochemical evaluation}

At the termination of experiments, tumor tissues from representative mice were sectioned, embedded in paraffin, and stained with hematoxylin and eosin for histopathologic evaluation. For immunohistochemical analysis, tissue sections $4 \mu \mathrm{m}$ in thickness were dewaxed and rehydrated in xylene and graded alcohols. Antigen retrieval was performed with $0.01 \mathrm{M}$ citrate buffer at $\mathrm{pH} 6.0$ for $20 \mathrm{~min}$ in a $95^{\circ} \mathrm{C}$ water bath. Slides were allowed to cool for another $20 \mathrm{~min}$, followed by sequential rinsing in PBS and TBS-T buffer. Endogenous peroxidase activity was quenched by incubation in TBS-T containing 3\% hydrogen peroxide. After washing in TBS-T for three times and blocking with $10 \%$ goat serum for $1 \mathrm{~h}$, sections were incubated with primary antibodies, washed three times in PBS, incubated with biotinylated secondary antibody for $1 \mathrm{~h}$, followed by incubation with a streptavidin-peroxidase complex for another $1 \mathrm{~h}$. After three additional washes in PBS, diaminobenzidine working solution was applied. Finally, the slides were counterstained in hematoxylin.

\section{Statistical analysis}

Tumor volumes, body weights, and percentage of apoptotic cells were represented as mean $\pm \mathrm{SD}$. The statistical significance of the difference between control and UA-treated groups was evaluated using Student's t test. $p<0.05$ or $p<0.01$ were considered significant.

\section{Author Contributions}

Conceived and designed the experiments: NG SC AB. Performed the experiments: NG SC AB E-HL JC DG ZY. Analyzed the data: NG AB JL XS ZZ. Contributed reagents/materials/analysis tools: NG SG ZZ. Wrote the paper: NG.

4. Grose KR, Bjeldanes LF (1992) Oligomerization of indole-3-carbinol in aqueous acid. Chem Res Toxicol 5: 188-193.

5. De Kruif CA, Marsman JW, Venekamp JC, Falke HE, Noordhoek J, et al. (1991) Structure elucidation of acid reaction products of indole-3-carbinol: detection in vivo and enzyme induction in vitro. Chem Biol Interact 80: 303-315.

6. Stresser DM, Blanchard AP, Turner SD, Erve JC, Dandeneau AA, et al. (2000) Substrate-dependent modulation of CYP3A4 catalytic activity: analysis of 27 test 
compounds with four fluorometric substrates. Drug Metab Dispos 28: 1440-1448.

7. Jin L, Qi M, Chen DZ, Anderson A, Yang GY, et al. (1999) Indole-3-carbinol prevents cervical cancer in human papilloma virus type 16 (HPV16) transgenic mice. Cancer Res 59: 3991-3997.

8. Wong GY, Bradlow L, Sepkovic D, Mehl S, Mailman J, et al. (1997) Doseranging study of indole-3-carbinol for breast cancer prevention. J Cell Biochem 28-29(suppl.): 111-116.

9. Hong C, Kim HA, Firestone GL, Bjeldanes LF (2002) 3,3-Diindolylmethane (DIM) induces a G(1) cell cycle arrest in human breast cancer cells that is accompanied by Sp1-mediated activation of p21(WAF1/CIP1) expression. Carcinogenesis 23: 1297-1305.

10. Howells LM, Gallacher-Horley B, Houghton CE, Manson MM, Hudson EA (2002) Indole-3-carbinol inhibits protein kinase B/Akt and induces apoptosis in the human breast tumor cell line MDA MB468 but not in the nontumorigenic HBL100 line. Mol Cancer Ther 1: 1161-1172.

11. Reed GA, Arneson DW, Putnam WC, Smith HJ, Gray JC, et al. (2006) Singledose and multiple-dose administration of indole-3-carbinol to women: pharmacokinetics based on 3, 3'-diindolylmethane. Cancer Epidemiol Biomarkers Prev 15: 2477-2481.

12. Ross JA, Kasum CM, Davies SM, Jacobs DR, Folsom AR, et al. (2002) Diet and risk of leukemia in the Iowa women's health study. Cancer Epidemiology, Biomarkers \& Prevention 11: 777-781.

13. Franke TF, Hornik CP, Segev L, Shostak GA, Sugimoto C (2003) PI3K/Akt and apoptosis: size matters. Oncogene 22: 8983-8998.

14. Vivanco I, Sawyers CL (2002) The phosphatidylinositol 3-Kinase-AKT pathway in human cancer. Nat Rev 2: 489-501.

15. Alessi DR, Andjelkovic M, Caudwell B, Cron P, Morrice N, et al. (1996) Mechanism of activation of protein kinase $\mathrm{B}$ by insulin and IGF-1. EMBO J 15: 6541-6551.

16. Datta SR, Brunet A, Greenberg ME (1999) Cellular survival: a play in three Akts. Genes Dev 13: 2905-2927.

17. Brunet A, Bonni A, Zigmond MJ, Lin MZ, Juo P, et al. (1999) Akt promotes cell survival by phosphorylating and inhibiting a Forkhead transcription factor. Cell 96: 857-868.

18. Cardone MH, Roy N, Stennicke HR, Salvesen GS, Franke TF, et al. (1998) Regulation of cell death protease caspase- 9 by phosphorylation. Science 282: 1318-1321.

19. Dhanasekaran DN, Reddy EP (2008) JNK signaling in apoptosis. Oncogene 27: 6245-6251.

20. Guo YL, Baysal K, Kang B, Yang LJ, Williamson J (1998) Correlation between sustained c-Jun N-terminal protein kinase activation and apoptosis induced by tumor necrosis factor-alpha in rat mesangial cells. J Biol Chem 273: 4027-4034.

21. Gong Y, Sohn H, Xue L, Firestone GL, Bjeldanes LF (2006) 3,3Diindolylmethane is a novel mitochondrial $\mathrm{H}^{+}$-ATP synthase inhibitor that can induce p21Cip1/Wafl expression by induction of oxidative stress in human breast cancer cells. Cancer Res 66: 4880-4887.

22. Rahman KM, Sarkar FH (2005) Inhibition of Nuclear Translocation of Nuclear Factor - $\mathrm{kB}$ Contributes to 3,3-Diindolylmethane-Induced Apoptosis in Breast Cancer Cells. Cancer Res 65: 364-371.

23. Chen Y, Xu J, Jhala N, Pawar P, Zhu ZB, et al. (2006) Fas-mediated apoptosis in cholangiocarcinoma cells is enhanced by $3,3^{\prime}$-Diindolylmethane through inhibition of AKT signaling and FLICE-like inhibitory protein. Am J Pathol 169: $1833-1842$

24. Bhuiyan MMR, Li Y, Banerjee S, Ahmed F, Wang Z, et al. (2006) Downregulation of androgen receptor by 3,3-Diindolylmethane contributes to inhibition of cell proliferation and induction of apoptosis in both hormonesensitive LNCaP and insensitive C4-2B prostate cancer cells. Cancer Res 66: $10064-10072$.

25. Nachshon-Kedmil M, Yannail S, Fares FA (2004) Induction of apoptosis in human prostate cancer cell line, PC3, by 3,3'-diindolylmethane through the mitochondrial pathway. Brit J Cancer 91: 1358-1363.

26. Kim AH, Khursigara G, Sun X, Franke TF, Chao MV (2001) Akt phosphorylates and negatively regulates apoptosis signal-regulating kinase 1 . Mol Cell Biol 21: 893-901.

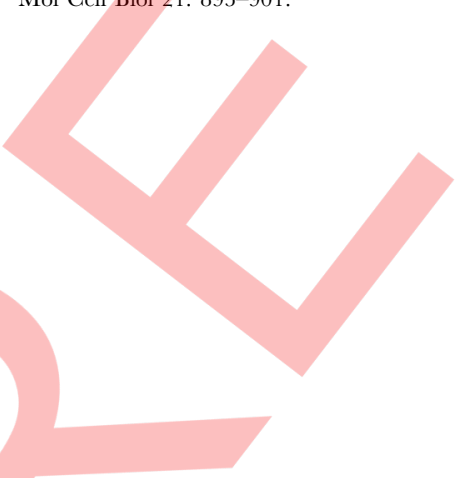

27. Burgering BM, Medema RH (2003) Decisions on life and death: FOXO Forkhead transcription factors are in command when PKB/Akt is off duty. J Leukoc Biol 73: 689-701.

28. Ozes ON, Mayo LD, Gustin JA, Pfeffer SR, Pfeffer LM, et al. (1999) NF-кB activation by tumor necrosis factor requires the Akt serine-threonine kinase. Nature 401: 82-85.

29. Cantley LC, Neel BG (1999) New insights into tumor suppression: PTEN suppresses tumor formation by restraining the phosphoinositide 3-kinase/Akt pathway. Proc Natl Acad Sci USA 96: 4240-4245.

30. Mao JH, To MD, Perez-Losada J, Wu D, Del Rosario R, et al. (2004) Mutually exclusive mutations of the Pten and ras pathways in skin tumor progression. Genes Dev 18: 1800-1805.

31. Kandel ES, Skeen J, Majewski N, Di Cristofano A, Pandolfi PP, et al. (2002) Activation of Akt/protein kinase B overcomes a $\mathrm{G}(2) / \mathrm{M}$ cell cycle checkpoint induced by DNA damage. Mol Cell Biol 22: 7831-7841.

32. Persad S, Attwell S, Gray V, Delcommenne M, Troussard A, et al. (2000) Inhibition of integrin-linked kinase (ILK) suppresses activation of protein kinase B/Akt and induces cell cycle arrest and apoptosis of PTEN-mutant prostate cancer cells. Proc Natl Acad Sci USA 97: 3207-3212.

33. Liu TC, Lin PM, Chang JG, Lee JP, Chen TP, et al. (2000) Mutation analysis of PTEN/MMAC1 in acute myeloid leukemia. Am J Hematol 63: 170-175.

34. Liu W, Akhand AA, Takeda K, Kawamoto Y, Itoigawa M, et al. (2003) Protein phosphatase 2A-linked and - unlinked caspase-dependent pathways for downregulation of Akt kinase triggered by 4-hydroxynonenal. Cell Death Differ 10: $772-781$.

35. Gao N, Rahmani M, Dent P, Grant S (2005) 2-Methoxyestradiol-induced apoptosis in human leukemia cells proceeds through a reactive oxygen species and Akt-dependent process. Oncogene 24: 3797-3809.

36. Bae J, Donigian JR, Hsueh AJ (2003) Tankyrase 1 interacts with Mcl-1 proteins and inhibits their regulation of apoptosis. J Biol Chem 278: 5195-5204.

37. Opferman JT, Iwasaki H, Ong CC, Suh H, Mizuno S-I, et al. (2005) Obligate role of anti-apoptotic MCL-1 in the survival of hematopoietic stem cells. Science 307: 1101-1104.

38. Kuo ML, Chuang SE, Lin MT, Yang SY (2001) The involvement of PI 3-K/ Akt-dependent up-regulation of Mcl-1 in the prevention of apoptosis of Hep3B cells by interleukin-6. Oncogene 20: 677-685.

39. Araki T, Hayashi M, Watanabe N, Kanuka H, Yoshino J, et al. (2002) Down regulation of Mcl-1 by inhibition of the PI3-K/Akt pathway is required for cell shrinkage-dependent cell death. Biochem Biophy Res Commun 290: 1275-1281.

40. Kyriakis JM, Avruch J (2001) Mammalian mitogen-activated protein kinase signal transduction pathways activated by stress and inflammation. Physiol Rev 81: 807-869.

41. Johnson GL, Lapadat R (2002) Mitogen-activated protein kinase pathways mediated by ERK, JNK, and p38 protein kinases. Science 298: 1911-1912.

42. Kim YS, Jhon DY, Lee KY (2004) Involvement of ROS and JNK1 in seleniteinduced apoptosis in Chang liver cells. Exp Mol Med 36: 157-164.

43. Zhang R, Al-Lamki R, Bai L, Streb JW, Miano JM, et al. (2004) Thioredoxin-2 inhibits mitochondria-located ASK1-mediated apoptosis in a JNK-independent manner. Circ Res 94: 1483-1491.

44. Song JJ, Lee YJ (2005) Dissociation of Akt1 from its negative regulator JIP1 is mediated through the ASK1-MEK-JNK signal transduction pathway during metabolic oxidative stress: a negative feedback loop. J Cell Biol 170: 61-72.

45. Tournier C, Hess P, Yang DD, Xu J, Turner TK, et al. (2000) Requirement of JNK for stress-induced activation of the cytochrome c-mediated death pathway. Science 288: 870-874

46. Harper JW, Adami GR, Wei N, Keyomarsi K, Elledge SJ (1993) The p21 cdkinteracting protein Cipl is a potent inhibitor of G1 cyclin dependent kinase. Cell 75: 805-816.

47. EL-Deiry WS (1998) p21/p53, cellular growth control and genomic integrity. Curr Top Microbiol Immunol 227: 121-137.

48. Gartel AL, Tyner AL (2002) The role of the cyclin-dependent kinase inhibitor p21 in apoptosis. Mol Cancer Ther 1: 639-649. 